\title{
Impacts of excision repair cross-complementing gene I (ERCCI), dihydropyrimidine dehydrogenase, and epidermal growth factor receptor on the outcomes of patients with advanced gastric
}

\section{cancer}

\section{J Matsubara', T Nishina ${ }^{2}$, Y Yamada*,', T Moriwaki², T Shimoda ${ }^{3}$, T Kajiwara ${ }^{2}$, TE Nakajima', K Kato', T Hamaguchi', Y Shimada', Y Okayama ${ }^{4}$, T Oka $^{4}$ and K Shirao'}

'Gastrointestinal Oncology Division, National Cancer Center Hospital, 5-I I Tsukiji Chuo-ku, Tokyo I040045, Japan; ${ }^{2}$ Department of Gastroenterology, National Hospital Organization Shikoku Cancer Center, 160 Kou Minamiumemoto-cho, Matsuyama 79I 0280, Japan; ${ }^{3}$ Clinical Laboratory Division, National Cancer Center Hospital, 5-I - I Tsukiji Chuo-ku, Tokyo I 040045, Japan; ${ }^{4}$ Personalized Medicine Research Laboratory, Taiho Pharmaceutical Co. Ltd, 224-2 Hiraishiebisuno Kawauchi-cho, Tokushima 7710194, Japan

Using laser-captured microdissection and a real-time RT-PCR assay, we quantitatively evaluated mRNA levels of the following biomarkers in paraffin-embedded gastric cancer (GC) specimens obtained by surgical resection or biopsy: excision repair crosscomplementing gene I (ERCCI), dihydropyrimidine dehydrogenase (DPD), methylenetetrahydrofolate reductase (MTHFR), epidermal growth factor receptor (EGFR), and five other biomarkers related to anticancer drug sensitivity. The study group comprised 140 patients who received first-line chemotherapy for advanced GC. All cancer specimens were obtained before chemotherapy. In patients who received first-line S-I monotherapy (69 patients), low MTHFR expression correlated with a higher response rate (low: $44.9 \%$ vs high: 6.3\%; $P=0.006$ ). In patients given first-line cisplatin-based regimens (combined with $\mathrm{S}-\mathrm{I}$ or irinotecan) (43 patients), low ERCCI correlated with a higher response rate (low: $55.6 \%$ vs high: | $8.8 \%$; $P=0.008$ ). Multivariate survival analysis of all patients demonstrated that high ERCCI (hazard ratio (HR): 2.38 (95\% Cl: 1.55-3.67)), high DPD (HR: 2.04 (I.37-3.02)), low EGFR (HR: 0.34 (0.20-0.56)), and an elevated serum alkaline phosphatase level (HR: I.00 (I.00 I- I.002)) were significant predictors of poor survival. Our results suggest that these biomarkers are useful predictors of clinical outcomes in patients with advanced GC.

British Journal of Cancer (2008) 98, 832-839. doi:I0.1038/sj.bjc.66042II www.bjcancer.com

Published online 29 January 2008

(c) 2008 Cancer Research UK

Keywords: gastric cancer; excision repair cross-complementing gene I; dihydropyrimidine dehydrogenase; epidermal growth factor receptor; prognostic factor

Gastric cancer (GC) is the second leading cause of cancer-related deaths worldwide, annually accounting for 40-50 deaths per 100000 population in Japan and 5-15 deaths per 100000 population in Europe (Parkin, 2001). During the past decade, newly developed cytotoxic drugs have been included in treatment regimens for GC. These new regimens have better response rates, often at the cost of higher incidences of severe adverse events (Ajani, 2005). This situation has created a greater need for diagnostic techniques that can predict clinical outcomes such as tumour response and survival in GC (Ichikawa, 2006). Considerable evidence suggests that the intratumour gene expressions of drug-metabolising enzymes, DNA repair enzymes, or angiogenic enzymes are useful predictors of treatment outcomes such as survival and the response to anticancer drugs (Backus et al, 2000; Ulrich et al, 2003; Marsh and McLeod, 2004). However, the clinical significance of these biomarkers remains unclear, especially in GC.

*Correspondence: Dr Y Yamada; E-mail: yayamada@ncc.go.jp Received 8 October 2007; revised 3 January 2008; accepted 3 January 2008; published online 29 January 2008
5-Fluorouracil (5-FU) and cisplatin are key drugs for the management of GC. Pharmacogenetic variability in metabolising enzymes of 5-FU and folate is a major determinant of the sensitivity to 5-FU and survival in GC (Lenz et al, 1996; Banerjee et al, 2002; Ichikawa et al, 2004; Napieralski et al, 2005). Several enzymes have key roles in the metabolic pathway of 5-FU and folate (Figure 1): thymidylate synthase (TS) is a target enzyme of $5-\mathrm{FU}$; dihydropyrimidine dehydrogenase (DPD) is a degrading enzyme of 5-FU; thymidine phosphorylase (TP) and orotate phosphoribosyl transferase (OPRT) are important metabolic enzymes; and dihydrofolate reductase (DHFR) and methylenetetrahydrofolate reductase (MTHFR) participate in folate metabolism. Lenz et al (1996) and Ichikawa et al (2004) have found that high TS mRNA expression in GC could predict poor clinical outcomes of treatment with 5-FU. Napieralski et al (2005) reported that high DPD expression in GC may correlate with poor survival and no response to 5-FU.

The cytotoxicity of cisplatin is attributed mainly to the induction of DNA intrastrand, interstrand, and DNA-protein crosslinks (Roberts and Thomson, 1979). Such DNA damage is 


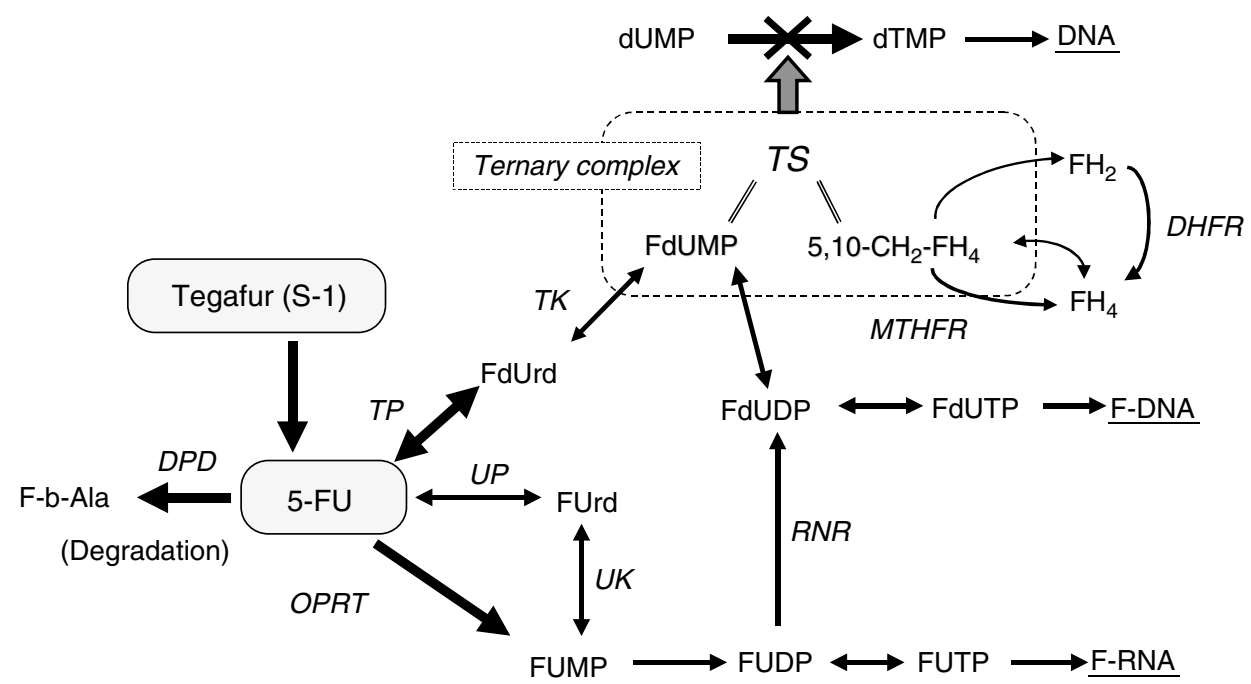

Figure I 5-Fluorouracil and folate metabolic pathways. Genes examined in our study are shown in bold. DPD, dihydropyrimidine dehydrogenase; DHFR, dihydrofolate reductase; MTHFR, methylenetetrahydrofolate reductase; OPRT, orotate phosphoribosyl transferase; TS, thymidylate synthase; TP, thymidine phosphorylase; . The official Human Genome Organization gene nomenclature is used. Common or alternative names for each gene can be found at http:// pharmacogenetics.wustl.edu.

thought to be repaired by the nucleotide excision pathway. Excision repair cross-complementing gene 1 (ERCC1) has a pivotal role in nucleotide excision repair and may promote the development of resistance to cisplatin (Dabholkar et al, 1992; Bramson and Panasci, 1993). Excision repair cross-complementing gene 1 is also associated with responses to cisplatin- and 5-FU-based chemotherapy in GC. Metzger et al (1998) reported that high ERCC1 expression in GC may be associated with poor survival and no response to cisplatin.

Other studies, however, have failed to confirm such correlations of the gene expressions of TS (Choi et al, 2001; Kwon et al, 2007), DPD (Ishikawa et al, 2000; Miyamoto et al, 2000), and ERCC1 (Napieralski et al, 2005) with the outcomes of chemotherapy. Further larger studies are thus required to confirm or refute previous claims.

This study was designed to further delineate the clinical implications of biomarkers and to identify potential predictors of the response to chemotherapy and survival in patients with GC. The epidermal growth factor receptor (EGFR) tyrosine kinase family and the vascular endothelial growth factor (VEGF) superfamily are also well-known mediators of tumour cell proliferation and tumour-related angiogenesis, which can influence tumour biology and survival (Carmeliet and Jain, 2000; Gamboa-Dominguez et al, 2004; Juttner et al, 2006). We tested the hypothesis that the clinical outcomes of chemotherapy (response rate, time to progression, and overall survival) in patients with advanced GC are related to the pretreatment intratumour mRNA levels of enzymes participating in critical pathways of drug resistance, such as 5-FU and folate metabolism (TS, DPD, TP, OPRT, DHFR, MTHFR), DNA repair (ERCC1), the EGFR signalling pathway (EGFR), and tumour-related angiogenesis (VEGF-A). We also compared the prognostic implications of these biomarkers with those of wellrecognised prognostic factors (Chau et al, 2004; Lee et al, 2007).

\section{PATIENTS AND METHODS}

\section{Patient eligibility}

Patients with a diagnosis of histologically proven advanced GC were eligible for the study. Inclusion criteria were as follows: unresectable, locally-advanced, or metastatic disease; no prior chemotherapy and no prior adjuvant/neoadjuvant chemotherapy; specimens of primary gastric adenocarcinomas were obtained before the start of chemotherapy by surgical resection or biopsy at the National Cancer Center Hospital (Tokyo, Japan) or National Hospital Organization Shikoku Cancer Center (Matsuyama, Japan); first-line chemotherapy was received at either of the hospitals; radiographically measurable disease; and written informed consent. The tissue samples were collected retrospectively from patients who met these criteria. Measurable disease was assessed by computed tomography. Response was evaluated according to the standard UICC guidelines as complete response (CR), partial response (PR), no change (NC), or progressive disease (PD) (Hayward et al, 1978). Tumour response and survival times as of December 2006 were confirmed in all patients. The response rate was calculated as the ratio of $(\mathrm{CR}+\mathrm{PR}) /$ $(\mathrm{CR}+\mathrm{PR}+\mathrm{NC}+\mathrm{PD})$. Written informed consent was obtained before treatment and evaluation of tumour samples. This study was approved by the institutional review boards of both hospitals.

\section{Clinical data}

The following clinical data were included in analyses: performance status, liver and peritoneal metastases, and laboratory data at the start of chemotherapy, including leukocyte and lymphocyte counts and the serum levels of alkaline phosphatase (ALP), lactate dehydrogenase (LDH), albumin, C-reactive protein, and tumour markers (CEA, CA19-9).

\section{Chemotherapy}

The following first-line chemotherapy regimens were administered to the patients in our study: $S-1$ monotherapy $(N=69)$, cisplatin plus S-1 $(N=14)$, cisplatin plus irinotecan $(N=29), 5-\mathrm{FU}$ monotherapy $(N=23)$, and other regimens $(5-\mathrm{FU}$ plus methotrexate, $N=2$; paclitaxel, $N=2$; uracil/ftorafur, $N=1$ ). For $\mathrm{S}-1$ monotherapy, patients received $\mathrm{S}-1\left(40 \mathrm{mg} \mathrm{m}^{-2}\right.$ twice daily) on days 1-28 of a 42-day cycle. Treatment with cisplatin plus S-1 consisted of cisplatin $\left(60 \mathrm{mg} \mathrm{m}^{-2}\right)$ on day 8 and $\mathrm{S}-1\left(40 \mathrm{mg} \mathrm{m}^{-2}\right.$ twice daily) on days 1-21 of a 35-day cycle. Treatment with cisplatin plus irinotecan consisted of cisplatin $\left(80 \mathrm{mg} \mathrm{m}^{-2}\right)$ on day 1 and irinotecan $\left(70 \mathrm{mg} \mathrm{m}^{-2}\right)$ on days 1 and 15 of a 28-day cycle. 
For 5-FU monotherapy, patients received 5-FU $\left(800 \mathrm{mg} \mathrm{m}^{-2}\right.$ day $\left.^{-1}\right)$ as a continuous infusion on days $1-5$ of a 28 -day cycle.

\section{Laboratory methods}

Ten-micrometre-thick sections obtained from identified areas with the highest tumour-cell concentration were mounted on uncoated glass slides. For histologic diagnosis, representative sections were stained with haematoxylin and eosin by standard methods. Before microdissection, sections were stained with nuclear fast red (American MasterTech Scientific, Lodi, CA, USA). The sections of interest were selectively isolated by laser-captured microdissection (PALM Microsystem, Leica, Wetzlar, Germany), according to standard procedures (Bonner et al, 1997). The dissected particles of tissue were transferred to a reaction tube containing $400 \mu \mathrm{l}$ of RNA lysis buffer.

The samples were homogenised and heated at $92^{\circ} \mathrm{C}$ for $30 \mathrm{~min}$. Fifty microlitres of $2 \mathrm{M}$ sodium acetate was added at $\mathrm{pH} 4.0$, followed by $600 \mu \mathrm{l}$ of freshly prepared phenol/chloroform/isoamyl alcohol $(250: 50: 1)$. The tubes were placed on ice for $15 \mathrm{~min}$ and then centrifuged at 13000 r.p.m. for $8 \mathrm{~min}$ in a chilled $\left(8^{\circ} \mathrm{C}\right)$ centrifuge. The upper aqueous phase was carefully removed. Glycogen $(10 \mu \mathrm{l})$ and $300-400 \mu \mathrm{l}$ of isopropanol were added. The tubes were chilled at $-20^{\circ} \mathrm{C}$ for $30-45 \mathrm{~min}$ to precipitate the RNA. The samples were washed in $500 \mu \mathrm{l}$ of $75 \%$ ethanol and air-dried for $15 \mathrm{~min}$. The pellet was resuspended in $50 \mu \mathrm{l}$ of $5 \mathrm{~mm}$ Tris. Finally, cDNA was prepared as described by Lord and colleagues (Lord et al, 2000).

Quantification of nine genes of interest and an internal reference gene ( $\beta$-actin) was performed with a fluorescence-based real-time detection method (ABI PRISM 7900 Sequence Detection System, TaqMan $^{\mathbb{R}}$, Perkin-Elmer (PE) Applied Biosystem, Foster City, CA, USA) using the standard curve method. The PCR reaction mixture consisted of $1200 \mathrm{nM}$ of each primer, $200 \mathrm{nM}$ of probe, $0.4 \mathrm{U}$ of AmpliTaq gold polymerase, $200 \mathrm{~nm}$ each of dATP, dCTP, dGTP, and dTTP, $3.5 \mathrm{mM}$ of $\mathrm{MgCl}_{2}$, and $1 \times$ Taqman buffer A containing a reference dye. The final volume of the reaction mixture was $20 \mu \mathrm{l}$ (all reagents from PE Applied Biosystems, Foster City, CA, USA). Cycling conditions were $50^{\circ} \mathrm{C}$ for $2 \mathrm{~min}$ and $95^{\circ} \mathrm{C}$ for $10 \mathrm{~min}$, followed by 46 cycles of $95^{\circ} \mathrm{C}$ for $15 \mathrm{~s}$ and $60^{\circ} \mathrm{C}$ for $1 \mathrm{~min}$. The primers and probes used are listed in Table 1. Gene expression values (relative mRNA levels) are expressed as ratios (differences between $C_{\mathrm{t}}$ values) between the gene of interest and an internal reference gene ( $\beta$-actin).

For each gene, we establish a usable $C_{\mathrm{t}}$ range for the data and document the precision of the measurements within the usable range. For maximum accuracy, we demonstrate that the slopes of the plots of $\Delta C_{\mathrm{t}} v s$ Log pg. RNA for target genes and the housekeeping gene (actin) demonstrate parallelism. Each replicate
$C_{\mathrm{t}}$ data point is the average of $C_{\mathrm{t}}$ values obtained in three PCR reactions. To compare the results of two different TaqMan plates with each other, the same standardised samples are analysed on every plate.

\section{Statistical analysis}

We examined the objective tumour response to chemotherapy, time to progression, and overall survival. Time to progression and overall survival were calculated as the period from the start of firstline chemotherapy until disease progression or death from any cause, respectively. If patients were lost to follow-up, data were censored at the date of the last evaluation.

To assess associations of gene expression levels with tumour response, time to progression, and overall survival, the expression levels of each gene were categorised into low and high values at optimal cutoff points. The maximal $\chi^{2}$ method (Halpern, 1982; Miller and Siegmund, 1982; Lausen and Schumacher, 1992) was used to determine which gene expression (optimal cutoff point) best segregated patients into poor- and good-outcome subgroups (in terms of likelihood of response and survival). To determine the corrected $P$-values on the basis of the maximal $\chi^{2}$ analysis, 2000 bootstrap-like simulations were used in univariate analyses to estimate the distribution of the maximal $\chi^{2}$ statistics under the null hypothesis of no association. The clinical laboratory data were treated as continuous variables. The estimates of hazard ratios (HRs) with 95\% CIs, on the basis of a Cox proportional hazards model, were used to provide quantitative summaries of the gene expression data.

All reported $P$-values are two-sided, and the level of statistical significance was set at $P<0.010$. Variables for multivariate analysis were selected by the Stepwise Method, using a significance level of $<0.010$ for entering into or remaining in the model. All analyses were performed using the statistical software package $\mathrm{R}$, version 2.4.1, and the SAS statistical package, version 9.1.3 (SAS Institute Inc., Cary, NC, USA).

\section{RESULTS}

A total of 140 patients were eligible for the study. Eighty-six patients (61\%) were recruited at the National Cancer Center Hospital and 54 patients (39\%) at the National Hospital Organization Shikoku Cancer Center. Chemotherapy began in July 1997 in the first patient and in June 2004 in the last patient. The demographic characteristics of the patients are shown in Table 2. There were $108(77 \%)$ men and $32(23 \%)$ women with a median age of 65 years. At the time of analysis, $131(94 \%)$ patients had died and nine $(6 \%)$ patients were alive.

Table I Primer and probe sequences for quantitative RT-PCR

\begin{tabular}{|c|c|c|c|}
\hline Gene & Forward primer $\left(5^{\prime}-3^{\prime}\right)$ & Reverse primer $\left(5^{\prime}-3^{\prime}\right)$ & Taqman ${ }^{\mathbb{R}}$ probe $\left(5^{\prime}-3^{\prime}\right)$ \\
\hline DPD & AGGACGCAAGGAGGGTाT & GTCCGCCGAGTCCTTACTGA & CAGTGCCTACAGTCTCGAGTCTGCCAGTG \\
\hline TP & CCTGCGGACGGAATCCT & GCTGTGATGAGTGGCAGGCT & CAGCCAGAGATGTGACAGCCACCGT \\
\hline DHFR & GTCCTCCCGCTGCTGTCA & GCCGATGCCCATGTTCTG & TTCGCTAAACTGCATCGTCGCTGTGTC \\
\hline MTHFR & CGGGTTAATTACCACCTTGTCAA & GCATTCGGCTGCAGTTCA & TGAAGGGTGAAAACATCACCAATGCCC \\
\hline $\mathrm{ERCCl}$ & GGGAATTTGGCGACGTAATTC & GCGGAGGCTGAGGAACAG & CACAGGTGCTCTGGCCCAGCACATA \\
\hline$\beta$-Actin & GAGCGCGGCTACAGCTT & TCCTTAATGTCACGCACGATTT & ACCACCACGGCCGAGCGG \\
\hline
\end{tabular}

Abbreviations: DHFR = dihydrofolate reductase; $D P D=$ dihydropyrimidine dehydrogenase; $E G F R=$ epidermal growth factor receptor; $E R C C I=$ excision repair crosscomplementing gene I; MTHFR = methylenetetrahydrofolate reductase; OPRT = orotate phosphoribosyl transferase; TP = thymidine phosphorylase; TS =thymidylate synthase; VEGF-A = vascular endothelial growth factor-A 
Table 2 Patient characteristics

\begin{tabular}{|c|c|c|}
\hline \multirow[b]{2}{*}{ Characteristic } & \multicolumn{2}{|r|}{ Patients } \\
\hline & No. & $\%$ \\
\hline All patients & 140 & \\
\hline \multicolumn{3}{|l|}{ Sex } \\
\hline Male & 108 & 77 \\
\hline Female & 32 & 23 \\
\hline \multicolumn{3}{|l|}{ Age (years) } \\
\hline Median & 65 & \\
\hline Range & $18-87$ & \\
\hline \multicolumn{3}{|l|}{ ECOG performance status } \\
\hline 0 & 70 & 50 \\
\hline I & 62 & 44 \\
\hline 2 & 8 & 6 \\
\hline \multicolumn{3}{|l|}{ Metastatic site } \\
\hline Lymph nodes & 87 & 62 \\
\hline Peritoneum & 43 & 31 \\
\hline Liver & 43 & 31 \\
\hline Lung & 8 & 6 \\
\hline Other & 9 & 6 \\
\hline \multicolumn{3}{|l|}{ Histological type } \\
\hline Intestinal & 60 & 43 \\
\hline Diffuse & 80 & 57 \\
\hline First-line chemotherapy regimen & & (Response rate $\left.{ }^{\mathrm{a}}(95 \% \mathrm{CI})\right)$ \\
\hline$S-1$ & 69 & $34.8(23.7-47.2)$ \\
\hline Cisplatin+S-I & 14 & $35.7(12.8-64.9)$ \\
\hline Cisplatin+irinotecan & 29 & $44.8(26.5-64.3)$ \\
\hline 5-FU & 23 & $4.3(0.1-22.0)$ \\
\hline 5-FU+methotrexate & 2 & 0 \\
\hline Paclitaxel & 2 & $50.0(1.3-98.7)$ \\
\hline Uracil/ftorafur $\left(\right.$ UFT $\left.^{\mathbb{R}}\right)$ & I & 0 \\
\hline
\end{tabular}

Abbreviation: $\mathrm{ECOG}=$ Eastern Cooperative Oncology Group. ${ }^{\text {a Response rate was }}$ calculated as the ratio of $(C R+P R) /(C R+P R+N C+P D)$

The chemotherapy regimens received by the patients and the response rates are also listed in Table 2. Many patients received S-1 monotherapy or cisplatin-based regimens as first-line treatment. The response rates with first-line chemotherapies in our study were comparable to those reported previously (Sakata et al, 1998; Boku et al, 1999; Ohtsu et al, 2003; Ajani et al, 2006).

\section{Gene expression levels of selected biomarkers, clinical} data, and overall survival in all patients

Gene expression levels of selected biomarkers were quantifiable in $88.6-99.3 \%$ of the 140 tumours (Table 3). Gene expression cutoff values in terms of overall survival were defined by using the maximal $\chi^{2}$ method, and corrected $P$-values were calculated for each single gene. On univariate analyses, overall survival in the study group as a whole correlated with the expression levels of ERCC1, DPD, EGFR, and TS, the serum levels of LDH and ALP, and performance status (Table 4). Using these significant mRNA factors on univariate analyses, we performed combined analysis. Patients with low mRNA expressions of ERCC1, DPD, TS, and high expression of EGFR $(N=30)$ had significantly longer overall survival than did the other patients $(N=106)$ (median overall survival, 22.0 vs 11.2 months; $P<0.001$, log-rank test; Figure 2). Multivariate analysis with a Cox proportional hazards model demonstrated that high ERCC1 expression (HR: 2.38 (1.55-3.67)), high DPD expression (HR: 2.04 (1.37-3.02)), low EGFR expression (HR: $0.34(0.20-0.56)$ ), and an elevated serum ALP level (HR: 1.00
Table 3 Gene expression levels of analysed biomarkers in all 140 patients

\begin{tabular}{lccc}
\hline & & \multicolumn{2}{c}{$\begin{array}{c}\text { mRA expression levels relative } \\
\text { to } \boldsymbol{\beta} \text {-actin }\left(\times \mathbf{I 0}^{-\mathbf{3}} \mathbf{)}\right.\end{array}$} \\
\cline { 3 - 4 } Gene & $\begin{array}{c}\text { No. of } \\
\text { patients (\%) }\end{array}$ & Median & Range \\
\hline TS & $139(99.3)$ & 2.81 & $0.84-16.05$ \\
DPD & $134(95.7)$ & 0.85 & $0.07-13.54$ \\
TP & $139(99.3)$ & 5.96 & $0.82-32.01$ \\
OPRT & $138(98.6)$ & 0.99 & $0.28-4.55$ \\
DHFR & $124(88.6)$ & 2.94 & $0.42-8.69$ \\
MTHFR & $136(97.1)$ & 1.24 & $0.25-8.20$ \\
ERCCI & $139(99.3)$ & 1.03 & $0.22-6.22$ \\
EGFR & $126(90.0)$ & 1.24 & $0.12-57.78$ \\
VEGF-A & $137(97.9)$ & 4.89 & $1.07-30.23$ \\
\hline
\end{tabular}

Abbreviations: DHFR = dihydrofolate reductase; DPD = dihydropyrimidine dehydrogenase; EGFR = epidermal growth factor receptor; ERCCI = excision repair crosscomplementing gene I; MTHFR = methylenetetrahydrofolate reductase; OPRT = orotate phosphoribosyl transferase; $\mathrm{TP}=$ thymidine phosphorylase; $\mathrm{TS}=$ thymidylate synthase; VEGF-A = vascular endothelial growth factor-A.

(1.001-1.002)) were significant predictors of poor survival (Table 4).

Gene expression levels of selected biomarkers, tumour response, and time to progression in patients treated with S-1 monotherapy or cisplatin-based regimens as first-line chemotherapy

To better understand the relation between mRNA levels of selected biomarkers and treatment outcomes with each chemotherapy regimen, we performed subgroup analyses. Gene expression cutoff values that best segregated patients into poor- and good-response subgroups were defined by using the maximal $\chi^{2}$ method. In patients given first-line S-1 monotherapy, low MTHFR (low: $44.9 \%$ vs high: $6.3 \%, P=0.006)$ gene expression alone correlated with a better response (Table 5). Expressions of the other eight genes did not correlate with response. In patients treated with first-line cisplatin-based regimens (combined with S-1 or irinotecan), low ERCC1 (low: $55.6 \%$ vs high: $18.8 \%, P=0.008)$ gene expression alone correlated with a better response (Table 5). Expressions of the other eight genes did not show any correlation with response.

Gene expression cutoff values and the corrected $P$-values for time to progression analyses were determined by the same methods as those used in the analyses of overall survival. In patients given first-line S-1 monotherapy, expression levels of DHFR and EGFR were significantly associated with the time to progression (Table 6). When $2.89 \times 10^{-3}$ was used as the cutoff value for DHFR, the median time to progression was 6.1 months in the low-expression group and 4.0 months in the high-expression group (corrected log-rank $P=0.003$, HR: 2.43 (95\% CI: $1.37-$ 4.29)). DHFR gene expression correlated with TS expression, with a Spearman's rank correlation coefficient of $0.456(P<0.001)$. When a cutoff value of $0.33 \times 10^{-3}$ was used for EGFR, the median time to progression was significantly longer in the high EGFR expression group (low: 2.8 months $v s$ high: 5.3 months, $P=0.007$, HR: $0.31(0.16-0.62))$. The association between expression levels of TS, DPD, TP, OPRT, MTHFR, ERCC1, and VEGF-A and the time to progression did not show significant results (Table 6).

In patients who received cisplatin-based regimens as first-line chemotherapy, expression levels of DPD and MTHFR correlated with the time to progression (Table 6). At a DPD cutoff value of $1.55 \times 10^{-3}$, the median time to progression was 4.6 months in the 
Table 4 Univariate analysis and Cox regression multivariate analysis of overall survival in all patients included in this study: correlation with mRNA expression levels and clinical data

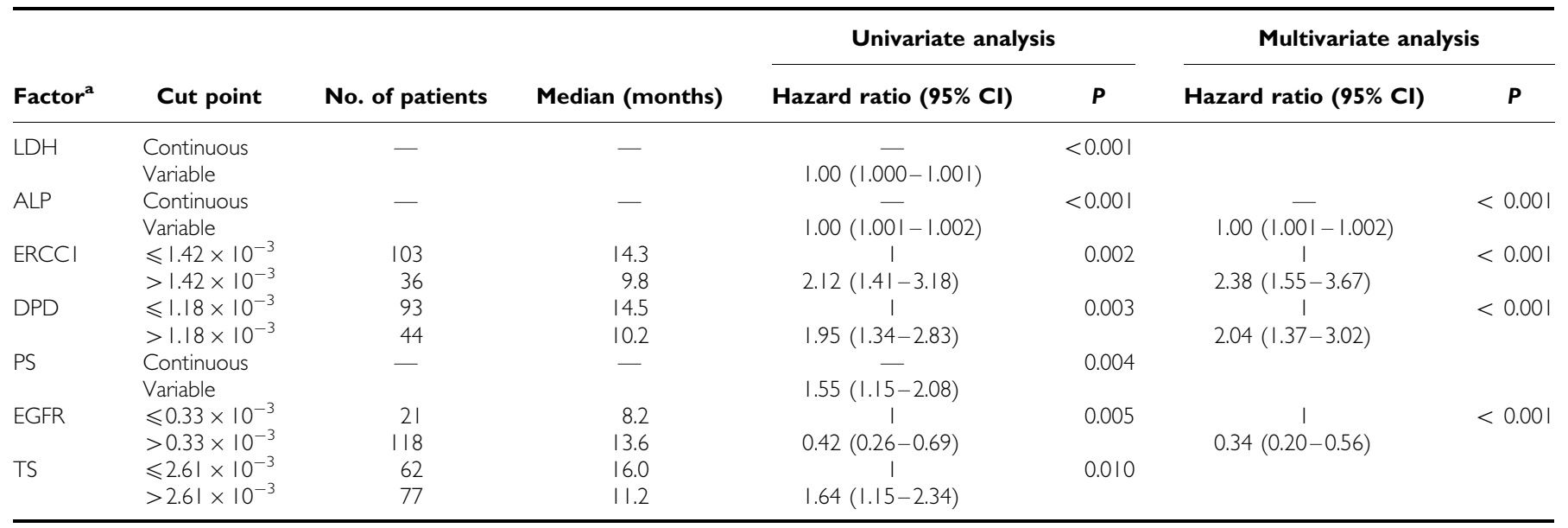

Abbreviations: ALP = alkaline phosphatase; DPD = dihydropyrimidine dehydrogenase; EGFR = epidermal growth factor receptor; $\mathrm{ERCCI}=$ excision repair cross-complementing gene I; $\mathrm{LDH}=$ lactate dehydrogenase; PS = performance status; TS = thymidylate synthase. Note: 'Cutoff point' for mRNA expression level was determined by the maximal $\chi^{2}$ method. ${ }^{a}$ Factors with $P$-values of $<0.010$ in univariate analyses are listed in ascending order of $P$-values. The stepwise method was used to select factors for multivariate analysis.

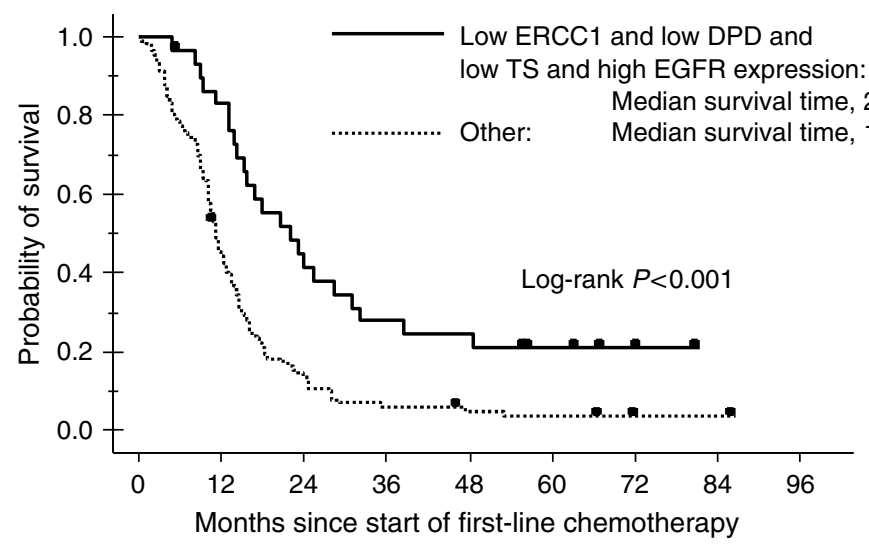

Number of patients at risk

$\begin{array}{lrrrrrrrrr}\text { Low ERCC1, low DPD, low TS } & 30 & 24 & 12 & 8 & 7 & 4 & 2 & 0 & 0 \\ \begin{array}{l}\text { and high EGFR expression } \\ \text { Other }\end{array} & 106 & 47 & 14 & 6 & 4 & 3 & 2 & 1 & 0\end{array}$

Figure 2 Kaplan-Meier plot of overall survival for all patients according to ERCCI, DPD, TS, and EGFR mRNA expression levels.

low DPD expression group as compared with only 1.2 months in the high DPD expression group $(P=0.008$, HR: $4.87(1.75-13.53))$. At a MTHFR cutoff value of $0.94 \times 10^{-3}$, the median time to progression was significantly longer in the high-expression group (low: 2.9 months vs high: 5.9 months, $P=0.007$, HR: $0.17(0.07-$ $0.42)$ ). The association between expression levels of the other seven genes and time to progression did not show significant results (Table 6).

\section{DISCUSSION}

In this study, we analysed mRNA expression levels of nine genes involved in 5-FU and folate metabolism, DNA repair, and angiogenesis in primary tumours from 140 patients with advanced GC. Our goal was to determine whether such expression levels are related to treatment outcomes such as survival and response. We found that high DPD expression, high ERCC1 expression, and low EGFR expression in GC specimens were significant predictors of poor survival in advanced GC. Recently, several studies have reported that patients' genetic profiles are related to the outcomes of cancer therapy (van 't Veer et al, 2002; Ruzzo et al, 2006). In colorectal cancer, since many studies have examined molecular predictors of outcomes during the past decade, TS, DPD, and TP were newly included in 'ASCO 2006 tumour marker guidelines in gastrointestinal cancer' (Locker et al, 2006). Because sufficient supporting evidence is lacking, however, the guidelines recommend that these biomarkers should not yet be used clinically to predict prognosis or treatment response. Further studies are therefore needed to more clearly define the relation between mRNA expression levels and clinical outcomes.

Our study showed that gene expression levels of DPD (related to the pharmacokinetics of fluoropyrimidines) and ERCC1 (related to the pharmacodynamics of cisplatin) had significant impacts on the overall survival of patients with advanced GC. This finding is consistent with the results of previous investigations (Metzger et al, 1998; Terashima et al, 2002; Napieralski et al, 2005). S-1, an oral DPD inhibitory fluoropyrimidine, is a novel antitumour drug 
Table 5 Gene expression levels and tumour response in patients with advanced gastric cancer according to first-line chemotherapy

\begin{tabular}{|c|c|c|c|c|c|c|c|c|c|c|}
\hline \multirow[b]{2}{*}{ Factor } & \multicolumn{5}{|c|}{ S-I monotherapy $(N=69)$} & \multicolumn{5}{|c|}{ Cisplatin-based regimens ${ }^{\mathrm{a}}(N=43)$} \\
\hline & $\begin{array}{c}\text { Total no. of } \\
\text { patients }\end{array}$ & $\begin{array}{l}\text { Cut point } \\
\left(\times 10^{-3}\right)\end{array}$ & $\begin{array}{l}\text { RR (\%) in low } \\
\text { group }\end{array}$ & $\begin{array}{l}R R(\%) \text { in } \\
\text { high group }\end{array}$ & $\boldsymbol{P}$ & $\begin{array}{l}\text { Total no. of } \\
\text { patients }\end{array}$ & $\begin{array}{l}\text { Cut point } \\
\left(\times 10^{-3}\right)\end{array}$ & $\begin{array}{l}\text { RR (\%) in low } \\
\text { group }\end{array}$ & $\begin{array}{l}R R(\%) \text { in } \\
\text { high group }\end{array}$ & $P$ \\
\hline TS & 66 & 3.67 & $45.2(19 / 42)$ & $20.8(5 / 24)$ & 0.044 & 43 & 3.43 & $50.0(15 / 30)$ & $23.1(3 / 13)$ & 0.103 \\
\hline DPD & 65 & 0.83 & $25.9(7 / 27)$ & $44.7(17 / 38)$ & 0.119 & 42 & 0.84 & $28.0(7 / 25)$ & $58.8(10 / 17)$ & 0.041 \\
\hline TP & 66 & 5.37 & $25.9(7 / 27)$ & $43.6(17 / 39)$ & 0.121 & 43 & 7.81 & $32.1(9 / 28)$ & $60.0(9 / 15)$ & 0.049 \\
\hline OPRT & 65 & 0.61 & $0(0 / 6)$ & $39.0(23 / 59)$ & 0.059 & 43 & 0.94 & $57.1(12 / 21)$ & $27.3(6 / 22)$ & 0.029 \\
\hline $\mathrm{ERCCl}$ & 65 & 0.92 & $50.0(14 / 28)$ & $24.3(9 / 37)$ & 0.033 & 43 & 1.18 & $55.6(15 / 27)$ & $18.8(3 / 16)$ & 0.008 \\
\hline EGFR & 66 & 1.20 & $45.7(16 / 35)$ & $25.8(8 / 31)$ & 0.094 & 43 & 1.39 & $51.7(15 / 29)$ & $21.4(3 / 14)$ & 0.049 \\
\hline VEGF-A & 65 & 2.70 & $54.5(6 / 11)$ & $31.5(17 / 54)$ & 0.104 & 43 & 6.52 & $53.8(14 / 26)$ & $23.5(4 / 17)$ & 0.022 \\
\hline
\end{tabular}

Abbreviations: $\mathrm{DHFR}=$ dihydrofolate reductase; $\mathrm{DPD}=$ dihydropyrimidine dehydrogenase; $E G F R=$ epidermal growth factor receptor; $E R C C I=$ excision repair crosscomplementing gene I; MTHFR = methylenetetrahydrofolate reductase; OPRT = orotate phosphoribosyl transferase; RR= response rate; TP=thymidine phosphorylase; TS = thymidylate synthase; VEGF-A = vascular endothelial growth factor-A. Note: 'Cutoff point' was determined by the maximal $\chi^{2}$ method. The level of significance was set at $P<0.010$. Significant values are shown in bold. ${ }^{a}$ Cisplatin-based regimens: cisplatin $+S-I$ and cisplatin+irinotecan.

Table 6 Univariate analyses of time to progression in patients with advanced gastric cancer treated with S-I monotherapy or cisplatin-based regimens as first-line chemotherapy: correlation with mRNA expression levels

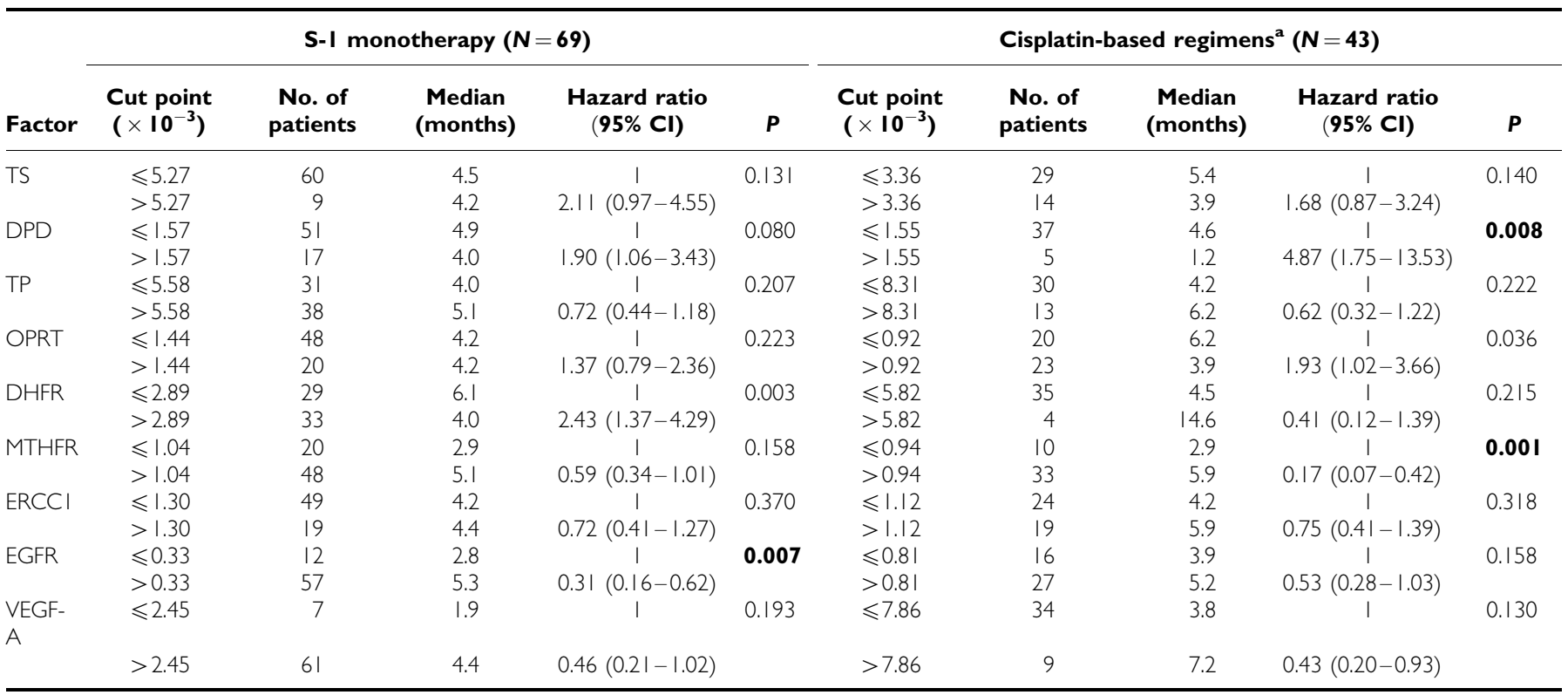

Abbreviations: $\mathrm{DHFR}=$ dihydrofolate reductase; $\mathrm{DPD}=$ dihydropyrimidine dehydrogenase; EGFR = epidermal growth factor receptor; $\mathrm{ERCCl}=$ excision repair crosscomplementing gene I; MTHFR = methylenetetrahydrofolate reductase; OPRT = orotate phosphoribosyl transferase; TP = thymidine phosphorylase; TS =thymidylate synthase; VEGF-A = vascular endothelial growth factor-A. Note: 'Cutoff point' was determined by the maximal $\chi^{2}$ method. The level of significance was set at $P<0.010$. Significant values are shown in bold. ${ }^{a}$ Cisplatin-based regimens: cisplatin+S-I and cisplatin+irinotecan.

combining tegafur (FT: a prodrug of 5-FU), gimeracil (CDHP: 5-chloro-2,4 dihydropyridine), and oteracil (Oxo: potassium oxonate) (Shirasaka et al, 1993, 1996). CDHP inhibits DPD activity and therefore prevents fluoropyrimidine degradation (Shirasaka et al, 1996). Oxo is a gastrointestinal tract adverse effect modulator (Shirasaka et al, 1993). In Japan, S-1 as monotherapy or combined with cisplatin is a standard regimen for advanced GC (Sakata et al, 1998; Ajani et al, 2006). Boku et al (2007) reported the result of a randomised controlled trial showing that S-1 is a promising standard regimen as compared with 5-FU, and Narahara et al (2007) showed that S-1 plus cisplatin is superior to S-1 alone. A multinational phase III study comparing S-1 plus cisplatin with 5FU plus cisplatin (control regimen) is now underway. In the future, S-1 combined with cisplatin may become a standard regimen not only in Japan but also worldwide. In our study, 129 patients (92\%) received S-1- or 5-FU-based regimens, and 73 patients (52\%) received cisplatin-based regimens as first-line or subsequent chemotherapy. Our results strongly suggest that tumours with high DPD and ERCC1 gene expression are unlikely to respond to current standard therapy, resulting in inadequate tumour control and poor outcomes. Patients with such tumours would require newly developed drugs and combined treatment modalities tailored to their specific needs.

Patients with low DHFR expression had a higher response rate and a longer time to progression while receiving S-1 monotherapy (Tables 5 and 6). DHFR is a key enzyme of folate metabolism. DHFR converts intracellular inactive dihydrofolate back to active tetrahydrofolate, which is reused in deoxythymidine- $5^{\prime}$-monophosphate synthesis (Figure 1) and is crucial for 5-FU antitumour activity. Sowers et al (2003) reported that E2F transcription factors 
may participate in the regulation of both TS and DHFR expression. We showed that a Spearman's correlation coefficient for TS/DHFR was $0.456(P<0.001)$. Backus et al $(2000)$ reported that low TS expression in vitro correlated with increased sensitivity to 5-FU. Several clinical studies have found that patients with low TS gene expression in primary GC correlate with a better tumour response and longer survival after 5-FU or S-1 treatment (Lenz et al, 1996; Ichikawa et al, 2004). The results of these studies suggest that low DHFR expression is associated with better clinical outcomes in patients given S-1 monotherapy, consistent with the results of our study. DHFR might thus be a candidate predictive biomarker of the response to S-1 treatment. Our data suggested that low DHFR expression may be an important determinant of tumour-cell sensitivity to $\mathrm{S}-1$.

In patients who received S-1 monotherapy, low MTHFR gene expression also correlated with a better tumour response (Table 5). Some studies have reported that the MTHFR 677T mutation, linked to the reduced activity of MTHFR, increases chemosensitivity to 5-FU (Cohen et al, 2003; Sohn et al, 2004), whereas others have had inconsistent results (Etienne et al, 2004; Ruzzo et al, 2006). Although MTHFR and DHFR are key enzymes in folate metabolism, the role of MTHFR gene expression in the antitumour activity of 5-FU remains controversial.

In patients given cisplatin-based regimens as first-line chemotherapy, low ERCC1 mRNA expression alone correlated with a better tumour response, confirming a previously reported association (Metzger et al, 1998). With respect to EGFR gene expression, evidence supporting a correlation between mRNA expression levels and survival or time to progression in GC is scant. Vallbohmer et al (2006) reported that high mRNA expression of EGFR was associated with a better response as well as longer progression-free and overall survival in patients with colorectal cancer who received irinotecan therapy, which is partially in accord with our findings. In contrast, GamboaDominguez et al (2004) found that strong membranous staining of EGFR on immunohistochemical analysis correlated with poor survival. The clinical implications of EGFR gene expression thus remain controversial.

In conclusion, our study provides evidence that high DPD, high ERCC1, and low EGFR gene expression levels in GC specimens and an elevated serum ALP level are risk factors for poor survival in patients with advanced GC. To the best of our knowledge, this is the first study showing that mRNA expression levels of molecular markers in primary GC had as much impact on survival outcomes as did well-recognised prognostic factors. The results of our analysis will hopefully provide a more rational basis for clinical decision-making, risk stratification of patients, and selection of management strategies as well as suggest benchmarks for future randomised controlled trials. Our relatively small sample size precludes drawing any firm conclusions, and candidate biomarkers must be validated in prospective studies. To confirm and extend the results of this exploratory study, larger studies are being planned in Japan.

\section{ACKNOWLEDGEMENTS}

We thank Dr Kathleen D Danenberg (Response Genetics, Inc, Los Angeles, CA, USA), Dr Peter V Danenberg (University of Southern California, Los Angeles, CA, USA), and Dr Masakazu Fukushima (Taiho Pharmaceutical Co. Ltd, Tokushima, Japan) for their support, advice, and many helpful discussions. This study was funded by Taiho Pharmaceutical Co. Ltd (Tokyo, Japan). $\mathrm{Y}$ Okayama is a senior researcher and $\mathrm{T}$ Oka is a director of Personalized Medicine Research Laboratory, Taiho Pharmaceutical Co. Ltd (Tokyo, Japan). All other authors declared no conflicts of interest. The sponsor of the study had no role in the study design, conduct of the study, data collection, data management and interpretation, preparation of the report, review of the report, or approval of the report. Y Okayama and T Oka, who are employed as disclosed above, had a partial role in data analysis.

\section{REFERENCES}

Ajani JA (2005) Evolving chemotherapy for advanced gastric cancer. Oncologist 10(Suppl 3): 49-58

Ajani JA, Lee FC, Singh DA, Haller DG, Lenz HJ, Benson III AB, Yanagihara R, Phan AT, Yao JC, Strumberg D (2006) Multicenter phase II trial of S-1 plus cisplatin in patients with untreated advanced gastric or gastroesophageal junction adenocarcinoma. J Clin Oncol 24: 663-667

Backus HH, Pinedo HM, Wouters D, Padron JM, Molders N, van Der Wilt CL, van Groeningen CJ, Jansen G, Peters GJ (2000) Folate depletion increases sensitivity of solid tumor cell lines to 5-fluorouracil and antifolates. Int J Cancer 87: 771-778

Banerjee D, Mayer-Kuckuk P, Capiaux G, Budak-Alpdogan T, Gorlick R, Bertino JR (2002) Novel aspects of resistance to drugs targeted to dihydrofolate reductase and thymidylate synthase. Biochim Biophys Acta 1587: $164-173$

Boku N, Ohtsu A, Shimada Y, Shirao K, Seki S, Saito H, Sakata Y, Hyodo I (1999) Phase II study of a combination of irinotecan and cisplatin against metastatic gastric cancer. J Clin Oncol 17: 319-323

Boku N, Yamamoto S, Shirao K, Doi T, Sawaki A, Koizumi W, Saito $\mathrm{H}$, Yamaguchi K, Kimura A, Ohtsu A (2007) Randomized phase III study of 5 -fluorouracil (5-FU) alone versus combination of irinotecan and cisplatin (CP) versus S-1 alone in advanced gastric cancer (JCOG9912). $J$ Clin Oncol 25(Suppl): 18S (abstr LBA4513)

Bonner RF, Emmert-Buck M, Cole K, Pohida T, Chuaqui R, Goldstein S, Liotta LA (1997) Laser capture microdissection: molecular analysis of tissue. Science 278: $1481-1483$

Bramson J, Panasci LC (1993) Effect of ERCC-1 overexpression on sensitivity of Chinese hamster ovary cells to DNA damaging agents. Cancer Res 53: 3237-3240

Carmeliet P, Jain RK (2000) Angiogenesis in cancer and other diseases. Nature 407: 249-257

Chau I, Norman AR, Cunningham D, Waters JS, Oates J, Ross PJ (2004) Multivariate prognostic factor analysis in locally advanced and metastatic esophago-gastric cancer - pooled analysis from three multicenter, randomized, controlled trials using individual patient data. J Clin Oncol 22: $2395-2403$

Choi J, Lim H, Nam DK, Kim HS, Cho DY, Yi JW, Kim HC, Cho YK, Kim MW, Joo HJ, Lee KB, Kim KB (2001) Expression of thymidylate synthase in gastric cancer patients treated with 5-fluorouracil and doxorubicinbased adjuvant chemotherapy after curative resection. $\mathrm{Br} J$ Cancer 84: $186-192$

Cohen V, Panet-Raymond V, Sabbaghian N, Morin I, Batist G, Rozen R (2003) Methylenetetrahydrofolate reductase polymorphism in advanced colorectal cancer: a novel genomic predictor of clinical response to fluoropyrimidine-based chemotherapy. Clin Cancer Res 9: $1611-1615$

Dabholkar M, Bostick-Bruton F, Weber C, Bohr VA, Egwuagu C, Reed E (1992) ERCC1 and ERCC2 expression in malignant tissues from ovarian cancer patients. J Natl Cancer Inst 84: 1512 - 1517

Etienne MC, Formento JL, Chazal M, Francoual M, Magne N, Formento P, Bourgeon A, Seitz JF, Delpero JR, Letoublon C, Pezet D, Milano G (2004) Methylenetetrahydrofolate reductase gene polymorphisms and response to fluorouracil-based treatment in advanced colorectal cancer patients. Pharmacogenetics 14: 785-792

Gamboa-Dominguez A, Dominguez-Fonseca C, Quintanilla-Martinez L, Reyes-Gutierrez E, Green D, Angeles-Angeles A, Busch R, Hermannstadter C, Nahrig J, Becker KF, Becker I, Hofler H, Fend F, Luber B (2004) Epidermal growth factor receptor expression correlates with poor survival in gastric adenocarcinoma from Mexican patients: a multivariate analysis using a standardized immunohistochemical detection system. Mod Pathol 17: 579-587 
Halpern J (1982) Maximally selected chi square statistics for small samples. Biometrics 38: $1017-1023$

Hayward JL, Rubens RD, Carbone PP, Heuson JC, Kumaoka S, Segaloff A (1978) Assessment of response to therapy in advanced breast cancer. A project of the programme on clinical oncology of the International union against cancer, Geneva, Switzerland. Eur J Cancer 14: 1291-1292

Ichikawa W (2006) Prediction of clinical outcome of fluoropyrimidinebased chemotherapy for gastric cancer patients, in terms of the 5-fluorouracil metabolic pathway. Gastric Cancer 9: 145-155

Ichikawa W, Takahashi T, Suto K, Yamashita T, Nihei Z, Shirota Y, Shimizu M, Sasaki Y, Hirayama R (2004) Thymidylate synthase predictive power is overcome by irinotecan combination therapy with $\mathrm{S}-1$ for gastric cancer. Br J Cancer 91: $1245-1250$

Ishikawa $\mathrm{Y}$, Kubota $\mathrm{T}$, Otani $\mathrm{Y}$, Watanabe $\mathrm{M}$, Teramoto T, Kumai $\mathrm{K}$, Takechi T, Okabe H, Fukushima M, Kitajima M (2000) Dihydropyrimidine dehydrogenase and messenger RNA levels in gastric cancer: possible predictor for sensitivity to 5-fluorouracil. Jpn J Cancer Res 91: $105-112$

Juttner S, Wissmann C, Jons T, Vieth M, Hertel J, Gretschel S, Schlag PM, Kemmner W, Hocker M (2006) Vascular endothelial growth factor-D and its receptor VEGFR-3: two novel independent prognostic markers in gastric adenocarcinoma. J Clin Oncol 24: 228-240

Kwon HC, Roh M, Oh S, Kim SH, Kim M, Kim JS, Kim HJ (2007) Prognostic value of expression of ERCC1, thymidylate synthase, and glutathione $S$-transferase P1 for 5-fluorouracil/oxaliplatin chemotherapy in advanced gastric cancer. Ann Oncol 18: 504-509

Lausen B, Schumacher M (1992) Maximally selected rank statistics. Biometrics 48: 73-85

Lee J, Lim T, Uhm J, Park K, Park S, Lee S, Park J, Park Y, Lim H, Sohn T, Noh J, Heo J, Park C, Kim S, Kang W (2007) Prognostic model to predict survival following first-line chemotherapy in patients with metastatic gastric adenocarcinoma. Ann Oncol 18: 886-891

Lenz HJ, Leichman CG, Danenberg KD, Danenberg PV, Groshen S, Cohen H, Laine L, Crookes P, Silberman H, Baranda J, Garcia Y, Li J, Leichman L (1996) Thymidylate synthase mRNA level in adenocarcinoma of the stomach: a predictor for primary tumor response and overall survival. J Clin Oncol 14: 176-182

Locker GY, Hamilton S, Harris J, Jessup JM, Kemeny N, Macdonald JS, Somerfield MR, Hayes DF, Bast Jr RC (2006) ASCO 2006 update of recommendations for the use of tumor markers in gastrointestinal cancer. J Clin Oncol 24: 5313-5327

Lord RV, Salonga D, Danenberg KD, Peters JH, DeMeester TR, Park JM, Johansson J, Skinner KA, Chandrasoma P, DeMeester SR, Bremner CG, Tsai PI, Danenberg PV (2000) Telomerase reverse transcriptase expression is increased early in the Barrett's metaplasia, dysplasia, adenocarcinoma sequence. J Gastrointest Surg 4: 135-142

Marsh S, McLeod HL (2004) Cancer pharmacogenetics. Br J Cancer 90: 8-11

Metzger R, Leichman CG, Danenberg KD, Danenberg PV, Lenz HJ, Hayashi K, Groshen S, Salonga D, Cohen H, Laine L, Crookes P, Silberman H, Baranda J, Konda B, Leichman L (1998) ERCC1 mRNA levels complement thymidylate synthase mRNA levels in predicting response and survival for gastric cancer patients receiving combination cisplatin and fluorouracil chemotherapy. J Clin Oncol 16: 309-316

Miller R, Siegmund D (1982) Maximally selected chi square statistics. Biometrics 38: $1011-1016$

Miyamoto S, Boku N, Ohtsu A, Yoshida S, Ochiai A, Okabe H, Fukushima M (2000) Clinical implications of immunoreactivity of thymidylate synthase and dihydropyrimidine dehydrogenase in gastric cancer treated with oral fluoropyrimidine (S-1). Study Group of S-1 for Gastric Cancer. Int J Oncol 17: 653-658

Napieralski R, Ott K, Kremer M, Specht K, Vogelsang H, Becker K, Muller M, Lordick F, Fink U, Rudiger Siewert J, Hofler H, Keller G (2005)
Combined GADD45A and thymidine phosphorylase expression levels predict response and survival of neoadjuvant-treated gastric cancer patients. Clin Cancer Res 11: 3025-3031

Narahara H, Koizumi W, Hara T, Takagane A, Akiya T, Takagi M, Miyashita K, Nishizaki T, Kobayashi O (2007) Randomized phase III study of S-1 alone versus S-1+ cisplatin in the treatment for advanced gastric cancer (The SPIRITS trial) SPIRITS: S-1 plus cisplatin $v s$ S-1 in RCT in the treatment for stomach cancer. J Clin Oncol 25(Suppl): 18S (abstr 4514)

Ohtsu A, Shimada Y, Shirao K, Boku N, Hyodo I, Saito H, Yamamichi N, Miyata Y, Ikeda N, Yamamoto S, Fukuda H, Yoshida S (2003) Randomized phase III trial of fluorouracil alone versus fluorouracil plus cisplatin versus uracil and tegafur plus mitomycin in patients with unresectable, advanced gastric cancer: The Japan Clinical Oncology Group Study (JCOG9205). J Clin Oncol 21: 54-59

Parkin DM (2001) Global cancer statistics in the year 2000. Lancet Oncol 2: $533-543$

Roberts JJ, Thomson AJ (1979) The mechanism of action of antitumor platinum compounds. Prog Nucleic Acid Res Mol Biol 22: 71-133

Ruzzo A, Graziano F, Kawakami K, Watanabe G, Santini D, Catalano V, Bisonni R, Canestrari E, Ficarelli R, Menichetti ET, Mari D, Testa E, Silva R, Vincenzi B, Giordani P, Cascinu S, Giustini L, Tonini G, Magnani M (2006) Pharmacogenetic profiling and clinical outcome of patients with advanced gastric cancer treated with palliative chemotherapy. J Clin Oncol 24: $1883-1891$

Sakata Y, Ohtsu A, Horikoshi N, Sugimachi K, Mitachi Y, Taguchi T (1998) Late phase II study of novel oral fluoropyrimidine anticancer drug S-1 (1 $\mathrm{M}$ tegafur- $0.4 \mathrm{M}$ gimestat- $1 \mathrm{M}$ otastat potassium) in advanced gastric cancer patients. Eur J Cancer 34: 1715-1720

Shirasaka T, Nakano K, Takechi T, Satake H, Uchida J, Fujioka A, Saito H, Okabe H, Oyama K, Takeda S, Unemi N, Fukushima M (1996) Antitumor activity of $1 \mathrm{M}$ tegafur-0.4 M 5-chloro-2,4-dihydroxypyridine-1 $\mathrm{M}$ potassium oxonate (S-1) against human colon carcinoma orthotopically implanted into nude rats. Cancer Res 56: $2602-2606$

Shirasaka T, Shimamoto Y, Fukushima M (1993) Inhibition by oxonic acid of gastrointestinal toxicity of 5-fluorouracil without loss of its antitumor activity in rats. Cancer Res 53: 4004-4009

Sohn KJ, Croxford R, Yates Z, Lucock M, Kim YI (2004) Effect of the methylenetetrahydrofolate reductase $\mathrm{C} 677 \mathrm{~T}$ polymorphism on chemosensitivity of colon and breast cancer cells to 5-fluorouracil and methotrexate. J Natl Cancer Inst 96: $134-144$

Sowers R, Toguchida J, Qin J, Meyers PA, Healey JH, Huvos A, Banerjee D, Bertino JR, Gorlick R (2003) mRNA expression levels of E2F transcription factors correlate with dihydrofolate reductase, reduced folate carrier, and thymidylate synthase mRNA expression in osteosarcoma. Mol Cancer Ther 2: 535 -541

Terashima M, Irinoda T, Fujiwara H, Nakaya T, Takagane A, Abe K, Yonezawa H, Oyama K, Inaba T, Saito K, Takechi T, Fukushima M (2002) Roles of thymidylate synthase and dihydropyrimidine dehydrogenase in tumor progression and sensitivity to 5-fluorouracil in human gastric cancer. Anticancer Res 22: 761-768

Ulrich CM, Robien K, McLeod HL (2003) Cancer pharmacogenetics: polymorphisms, pathways and beyond. Nat Rev Cancer 3: $912-920$

Vallbohmer D, Iqbal S, Yang DY, Rhodes KE, Zhang W, Gordon M, Fazzone W, Schultheis AM, Sherrod AE, Danenberg KD, Lenz HJ (2006) Molecular determinants of irinotecan efficacy. Int $J$ Cancer 119: $2435-2442$

van 't Veer LJ, Dai $H$, van de Vijver MJ, He YD, Hart AA, Mao M, Peterse HL, van der Kooy K, Marton MJ, Witteveen AT, Schreiber GJ, Kerkhoven RM, Roberts C, Linsley PS, Bernards R, Friend SH (2002) Gene expression profiling predicts clinical outcome of breast cancer. Nature 415: $530-536$ 